\title{
Time-domain representation of ventricular-arterial coupling as a windkessel and wave system
}

\author{
Jiun-Jr Wang, ${ }^{1}$ Aoife B. O'Brien, ${ }^{4}$ Nigel G. Shrive, ${ }^{2}$ Kim H. Parker, ${ }^{3}$ and John V. Tyberg ${ }^{1}$ \\ Departments of ${ }^{1}$ Medicine and Physiology/Biophysics and ${ }^{2}$ Civil Engineering, University of Calgary, \\ Calgary, Alberta, Canada T2N 4N1; ${ }^{3}$ Physiological Flow Studies Group, Department of Bioengineering, \\ Imperial College of Science, Technology, and Medicine, London SW7 2AZ, United Kingdom; and \\ ${ }^{4}$ National University of Ireland, National Centre for Biomedical Engineering Science, Galway, Ireland
}

Submitted 28 February 2002; accepted in final form 10 December 2002

\begin{abstract}
Wang, Jiun-Jr, Aoife B. O'Brien, Nigel G. Shrive, Kim H. Parker, and John V. Tyberg. Time-domain representation of ventricular-arterial coupling as a windkessel and wave system. Am $J$ Physiol Heart Circ Physiol 284: H1358-H1368, 2003. First published December 12, 2002; 10.1152/ajpheart.00175.2002.-The differences in shape between central aortic pressure $\left(\mathrm{P}_{\mathrm{Ao}}\right)$ and flow waveforms have never been explained satisfactorily in that the assumed explanation (substantial reflected waves during diastole) remains controversial. As an alternative to the widely accepted frequency-domain model of arterial hemodynamics, we propose a functional, time-domain, arterial model that combines a blood conducting system and a reservoir (i.e., Frank's hydraulic integrator, the windkessel). In 15 anesthetized dogs, we measured $\mathrm{P}_{\text {Ao }}$, flows, and dimensions and calculated windkessel pressure $\left(\mathrm{P}_{\mathrm{Wk}}\right)$ and volume $\left(\mathrm{V}_{\mathrm{Wk}}\right)$. We found that $\mathrm{P}_{\mathrm{Wk}}$ is proportional to thoracic aortic volume and that the volume of the thoracic aorta comprises $45.1 \pm 2.0 \%$ (mean \pm $\mathrm{SE}$ ) of the total $\mathrm{V}_{\mathrm{Wk}}$. When we subtracted $\mathrm{P}_{\mathrm{Wk}}$ from $\mathrm{P}_{\mathrm{Ao}}$, we found that the difference (excess pressure) was proportional to aortic flow, thus resolving the differences between $\mathrm{P}_{\text {Ao }}$ and flow waveforms and implying that reflected waves were minimal. We suggest that $\mathrm{P}_{\text {Ao }}$ is the instantaneous summation of a time-varying reservoir pressure (i.e., $\mathrm{P}_{\mathrm{Wk}}$ ) and the effects of (primarily) forward-traveling waves in this animal model.
\end{abstract}

aortic pressure; aortic flow; compliance; left ventricular ejection; waves

FOR AS LONG AS CARDIOVASCULAR PHYSIOLOGISTS have been able to measure pressure and flow in the ascending aorta, they have puzzled over the obvious differences in shape between the two waveforms. One way of explaining the measured differences in pressure and flow waveforms in the ascending aorta would be the existence of reflected waves because, although the changes in pressure and flow in the reflected waves are also proportional to each other, the sign of the constant of proportionality is reversed. Thus a reflected wave that reinforces the pressure change caused by the forward wave will have a canceling effect on the flow. However, despite many attempts, it has never been demonstrated that the effects of wave reflection are sufficient to explain the large, qualitative differences in the aor-

Address for reprint requests and other correspondence: J. V. Tyberg, Univ. of Calgary, Health Sciences Centre, 3330 Hospital Dr. NW, Calgary, Alberta, Canada T2N 4N1 (E-mail: jtyberg@ucalgary.ca). tic pressure $\left(\mathrm{P}_{\mathrm{Ao}}\right)$ and flow waveforms (24), particularly during diastole when $\mathrm{P}_{\text {Ao }}$ declines incrementally from a high level and aortic flow remains essentially zero. Indeed, Milnor (20) remarked that the properties of the aortic tree in the normal young animal are those of an almost perfect diffuser (i.e., it generates far fewer reflections than the best man-made distribution network). Many other suggestions for the resolution of this paradox have been advanced, but none have found general acceptance. [See both Milnor (20) and Nichols and O'Rourke (22) for exhaustive but inconclusive discussions of this problem.]

In contrast to the prevailing frequency-domain concepts, according to which $\mathrm{P}_{\mathrm{Ao}}$ and flow waveforms are separated into mean and oscillatory components $(2,12$, $20,24,28)$, we propose a new time-domain approach based on the two major functional properties of the arterial system, properties that describe the reservoir function and those that describe the wave-transmitting function. The reservoir properties of the system are those by which blood and potential energy are stored, to be subsequently expended in peripheral perfusion $(41,42)$. In this regard, the aorta can be considered to be a zero-dimensional system (33), in which pressure and volume changes are functions of time only. During systole, the ejected stroke volume increases the reservoir volume and thus the reservoir pressure. During diastole, outflow exceeds inflow so reservoir volume decreases, and this is the simple explanation for the decrease in pressure. This reservoir mechanism has been simulated using the hydraulic-integrator windkessel model. The wave-transmitting properties of the system are those by which forward- and backwardtraveling pressure-velocity waves are supported (23, $25,43)$. In this regard, the aorta can be considered to be a one-dimensional system (25) in which pressure and velocity are functions of distance as well as time. The aorta may be analogous to a canal lock, upon whose surface waves can propagate [somewhat similar to the classical soliton (30-32, 49)] and whose hydrostatic pressure is a simple function of the water level.

The costs of publication of this article were defrayed in part by the payment of page charges. The article must therefore be hereby marked "advertisement" in accordance with 18 U.S.C. Section 1734 solely to indicate this fact. 
Following Frank (33), we consider the windkessel to be a hydraulic integrator whose change in pressure $\left(\Delta \mathrm{P}_{\mathrm{Wk}}\right)$ is directly related to its change in volume $\left(\Delta \mathrm{V}_{\mathrm{Wk}}\right)$ and, inversely, to its compliance. [The rate of change of $\mathrm{V}_{\mathrm{Wk}}$ is simply the difference between the inflow from the left ventricle $\left(Q_{\text {in }}\right)$ and the outflow to the periphery $\left(\mathrm{Q}_{\text {out }}\right)$.] In considering wave propagation on a reservoir, Lighthill (15) proposed that the measured pressure was the sum of the reservoir pressure and the pressure due to wave motion, which he called "excess pressure" $\left(\mathrm{P}_{\mathrm{ex}}\right)$. Assuming that the windkessel can be considered as a quasisteady reservoir with respect to the waves, we suggest that measured central $\mathrm{P}_{\mathrm{Ao}}$ (at the valve) should likewise be considered as the sum of a calculated $\mathrm{P}_{\mathrm{Wk}}$ and $\mathrm{P}_{\mathrm{ex}}$. Having thus defined $\mathrm{P}_{\mathrm{ex}}$ (i.e., $\mathrm{P}_{\mathrm{ex}}=\mathrm{P}_{\mathrm{Ao}}-\mathrm{P}_{\mathrm{Wk}}$ ), we find the $\mathrm{P}_{\mathrm{ex}}$ waveform to be strikingly similar to that of central aortic flow, $Q_{i n}$. Because these waveforms are so similar, a plot of $\mathrm{P}_{\mathrm{ex}}$ versus $Q_{i n}$ can be well approximated by a line, the slope of which (in units of resistance) is not different from the value of the so-called characteristic impedance.

Our findings suggest that the hemodynamics of aortic ejection must be reinterpreted, and, with this understanding of the windkessel as a hydraulic integrator, some of the discrepancies between theoretical models and experimental observations might be resolved.

\section{METHODS}

\section{Theory}

We propose that $\mathrm{P}_{\text {Ao }}$ be represented as the sum of a time-varying reservoir pressure (independent of distance) and a $\mathrm{P}_{\mathrm{ex}}$ that varies in time $(t)$ and with distance along the arteries $(x): \mathrm{P}_{\mathrm{Ao}}(x, t)=\mathrm{P}_{\mathrm{Wk}}(t)+\mathrm{P}_{\mathrm{ex}}(x, t)$.

Windkessel theory. The variation of aortic $\mathrm{P}_{\mathrm{Wk}}$ is determined by the difference between inflow and outflow and the change in volume (33)

$$
\frac{\mathrm{dP}_{\mathrm{Wk}}(t)}{\mathrm{d} t}=\frac{\mathrm{dP}_{\mathrm{Wk}}}{\mathrm{dV}_{\mathrm{Wk}}} \frac{\mathrm{dV}_{\mathrm{Wk}}(t)}{\mathrm{d} t}=\frac{\mathrm{Q}_{\mathrm{in}}(t)-\mathrm{Q}_{\mathrm{out}}(t)}{C}
$$

where $C=d V_{\mathrm{Wk}} / \mathrm{dP}_{\mathrm{Wk}}$ and is the compliance of the whole arterial tree (37) and assumed to be constant. If the outflow can be described by a simple resistive relationship, $\mathrm{Q}_{\text {out }}(t)=$ $\left[\mathrm{P}_{\mathrm{wk}}(t)-\mathrm{P}_{\infty}\right] / R$ [where the outflow is assumed to be driven by the difference between $\mathrm{P}_{\mathrm{wk}}$ and the asymptotic pressure of the diastolic exponential decay $\left.\left(\mathrm{P}_{\infty}\right)(34)\right]$, at which flow from the arteries to the veins ceases. So defined, $R$ is the effective resistance of the peripheral systemic circulation.

Substituting $\mathrm{Q}_{\text {out }}$ in terms of $\mathrm{P}_{\mathrm{Wk}}$ and $\mathrm{P}_{\infty}, E q .1$ can be rewritten in terms of $\mathrm{P}_{\mathrm{Wk}}$

$$
\frac{\mathrm{dP}_{\mathrm{Wk}}(t)}{\mathrm{d} t}+\frac{\mathrm{P}_{\mathrm{Wk}}(t)-\mathrm{P}_{\infty}}{R C}=\frac{\mathrm{Q}_{\mathrm{in}}(t)}{C}
$$

and the general solution is

$$
\mathrm{P}_{\mathrm{Wk}}(t)-\mathrm{P}_{\infty}=\left(\mathrm{P}_{0}-\mathrm{P}_{\infty}\right) e^{\frac{-1}{R C}}+e^{\frac{-t}{R C}} \int_{t_{o}}^{t} \frac{\mathrm{Q}_{\mathrm{in}}\left(t^{\prime}\right)}{C} e^{\frac{t^{\prime}}{R C} \mathrm{~d} t^{\prime}}
$$

in which $t_{0}$ and $\mathrm{P}_{0}$ are the time and pressure at the onset of ejection. During diastole, when $Q_{\text {in }}=0$, the solution is a simple exponential, falling with the time constant $(\tau)=R C$.
To solve Eq. 3, $R, C$, and $\mathrm{P}_{\infty}$ have to be determined using experimental data. It is believed that waves are minimal during approximately the last two-thirds of diastole (38); thus $\mathrm{P}_{\mathrm{Ao}}$ must approximate $\mathrm{P}_{\mathrm{Wk}}$ during this time. $\mathrm{P}_{\infty}$ and $\tau$ can then be determined by fitting the late-diastolic $\mathrm{P}_{\mathrm{Ao}}$ data by $E q .3$.

Several methods have been proposed for the fitting of a windkessel to measured arterial pressure $(38,48)$. We adopted an alternative approach where the parameters $R, C$, and $\mathrm{P}_{\infty}$, which determine $\mathrm{P}_{\mathrm{wk}}$, are calculated iteratively using a nonlinear search algorithm to minimize the mean square error over the last two-thirds of diastole. The minimization is done using the Matlab routine "fminsearch," which uses the Nelder-Mead simplex (direct search) method. As initial estimates, we used $C=0.5 \mathrm{ml} / \mathrm{mmHg}, \mathrm{P}_{\infty}=30$ $\mathrm{mmHg}$, and $R$ calculated from the mean of the measured pressure and flow rate over the cardiac cycle. Although up to 20 iterations may be required for convergence, the method is robust.

Wave theory. Arterial wave theory is based on one-dimensional flow in an elastic tube (25-27). If frictional loss is neglected, wave equations can be derived from the conservation of mass and momentum in terms of the cross-sectional area $(A)$ and velocity $(U)(15,46)$

$$
\begin{gathered}
A_{t}+(U A)_{x}=0 \\
U_{t}+U U_{x}+\frac{\mathrm{P}_{x}}{\rho}=0
\end{gathered}
$$

where $\rho$ is the density of blood.

Lighthill (15) states that a wave is a propagated disturbance and that it is driven by $\mathrm{P}_{\mathrm{ex}}$, which he defined as the difference between the measured pressure and the undisturbed reservoir pressure. Because the aortic windkessel functions as a reservoir and its rate of pressure change is low relative to the pressure changes associated with the propagation of waves, we appropriated and modified Lighthill's concept and here define $\mathrm{P}_{\text {ex }}$ as the difference between $\mathrm{P}_{\mathrm{Ao}}$ and $\mathrm{P}_{\mathrm{Wk}}$, i.e., $\mathrm{P}_{\mathrm{ex}}=\mathrm{P}_{\mathrm{Ao}}-\mathrm{P}_{\mathrm{Wk}}$. The cross-sectional area $A$ for the wave equations is described as a function of $\mathrm{P}_{\mathrm{ex}}$, i.e., $A=$ $f\left(\mathrm{P}_{\mathrm{ex}}\right)$. The mass and momentum equations can be written in terms of $\mathrm{P}_{\mathrm{ex}}$ and $U$. Equation 4 can then be described as

$$
\left(\mathrm{P}_{\mathrm{ex}}\right)_{t}+U\left(\mathrm{P}_{\mathrm{ex}}\right)_{x}+\rho c^{2} U_{x}=-\frac{\mathrm{dP}_{\mathrm{Wk}}}{\mathrm{d} t}
$$

where $c$ is the wave speed $[c=1 / \sqrt{\rho D}$, where $D$ is the distensibility of the artery $\left.\left(D=1 / A \times \mathrm{d} A / \mathrm{dP}_{\text {ex }}\right)\right]$. These equations are hyperbolic, and a general solution can be obtained using the method of characteristics. The arguments leading to the solution are subtle and somewhat difficult, but the solution is surprisingly simple. Any disturbance introduced into the artery will produce wavefronts that travel forward and backward with speeds of $c \pm U$. The changes in pressure and velocity across these wavefronts are related by

$$
\mathrm{dP}_{\text {ex } \pm} \pm \rho c \mathrm{~d} U_{ \pm}=0
$$

where + refers to forward-traveling waves and - refers to backward-traveling waves. They can also be described in term of the volume flow rate, $\mathrm{dP}_{\mathrm{ex} \pm}= \pm \rho c / A \times \mathrm{dQ}_{ \pm}$, which is the water hammer equation. $\rho c / A$ is the characteristic impedance, which was defined as the pressure-to-flow ratio of a forward-traveling wave (20).

\section{Experimental Preparation and Protocol}

Studies were performed on 15 healthy mongrel dogs weighing between 18 and $29 \mathrm{~kg}$. Dogs were anesthetized by 
thiopental sodium (20 $\mathrm{mg} / \mathrm{kg}$ ), followed by fentanyl citrate $\left(30 \mu \mathrm{g} \cdot \mathrm{kg}^{-1} \cdot \mathrm{h}^{-1}\right)$ and ventilated with a 1:1 nitrous oxideoxygen mixture. The rate of a constant-volume respirator (tidal volume $=15 \mathrm{ml} / \mathrm{kg}$, model 607, Harvard Apparatus; Natick, MA) was adjusted to maintain normal blood gas tensions and $\mathrm{pH}$. Body temperature was maintained at $37^{\circ} \mathrm{C}$ using a circulating water warming blanket and a heating lamp. Lactated Ringer solution was infused through the jugular vein to maintain mean aortic blood pressure $>80$ $\mathrm{mmHg}$. To enable us to equate thoracic aortic outflows to the aortic inflow, all the intercostal arteries were occluded using surgical clips. The spontaneous heart rates varied; the hearts were paced as slowly as possible (model S88, Grass Instruments; Quincy, MA).

We measured pressures in the left ventricle and at the aortic root using high-fidelity catheter-tip manometers (Millar Instruments; Houston, TX) and flows at the aortic root at the sources of the brachiocephalic artery, left subclavian artery, and aorta at the diaphragm using ultrasonic flow probes (Transonic Systems; Ithaca, NY). The left ventricular pressure catheter was introduced through the apex. Aortic root pressure was measured by introducing a micromanometer (2-Fr) inserted from the right subclavian artery retrograde through the brachiocephalic artery into the root of the aorta, $\sim 1.5 \mathrm{~cm}$ from the valve. The aortic root manometer was positioned within $1 \mathrm{~cm}$ of the aortic root flow probe. Diameters were measured at the aortic root and diaphragm, located within $1 \mathrm{~cm}$ of the respective flow probes, using pairs of ultrasonic crystals (Sonometrics; London, Ontario, Canada). (From these diameters, the volume of the thoracic aorta was calculated, assuming that it was shaped as a truncated cone.) After control recordings were taken, in 12 dogs, a counterpulsation balloon was introduced into the abdominal aorta just proximal to the aortoiliac bifurcation, which could be rapidly inflated and deflated to produce backward-traveling compression and expansion waves at any time during the cardiac cycle. With the use of a two-channel laboratory stimulator with variable and independent delay controls (model S88, Grass Instruments), we both stimulated the heart and triggered the counterpulsation pump such that the backward-traveling waves were made to arrive at the left ventricle at any chosen time during systolic ejection. The backward waves could be identified by superimposing the pressure and flow waveforms of the balloon-inflated beat over those of the immediately preceding control beat.

In four paced dogs, we measured left ventricular pressure (through the apex) and $\mathrm{P}_{\text {Ao }}$ [through the right subclavian with a micromanometer (2-Fr)], and a third manometer was inserted from the femoral artery and advanced retrogradely to the aortic root. Flow at the aortic root, $Q_{\text {in }}$, was also recorded. The third manometer was pulled back by $2-\mathrm{cm}$ increments to the femoral artery, pressures being recorded at each position with the ventilator turned off at end-expiration. Three-dimensional plots of $\mathrm{P}_{\text {Ao }}$ versus time and distance from the aortic valve were constructed, taking the aortic root pressure as a temporal reference.

\section{RESULTS}

Figure $1 A$ shows typical measured left ventricular pressure and $\mathrm{P}_{\mathrm{Ao}}$, calculated $\mathrm{P}_{\mathrm{Wk}}$, and $\mathrm{P}_{\infty}$. $\mathrm{P}_{\mathrm{Wk}}$ begins to increase $30-50 \mathrm{~ms}$ after $\mathrm{P}_{\mathrm{Ao}}$, when aortic inflow exceeds outflow, and it continues to increase until inflow decreases to equal outflow (note the vertical dashed lines). During the latter part of diastole, $\mathrm{P}_{\mathrm{Wk}}$ approximates $\mathrm{P}_{\text {Ao }}$ very closely because we curve fit this segment in our determination of the windkessel pa- rameters. The difference between $\mathrm{P}_{\mathrm{Ao}}$ and $\mathrm{P}_{\mathrm{Wk}}$ is $\mathrm{P}_{\mathrm{ex}}$, which is plotted with the measured aortic inflow $Q_{\text {in }}$ in Fig. $1 B$. The $\mathrm{P}$ and $\mathrm{Q}$ scales were adjusted to show that the two waveforms are almost identical in shape, which indicates that the effects of backward-traveling waves are minimal under these conditions. Figure $1 C$ shows the intensity (i.e., normalized power) of forwardand backward-traveling waves (40). The forward-traveling compression wave, which defines the power required to accelerate the stroke volume, is the protypical example of a "wave" as defined in this paper.

Figure 2 is a plot of $P_{\text {ex }}$ versus $Q_{\text {in }}$, with the solid line suggesting that the left ventricular stroke volume is injected into the windkessel by a mechanism that is effectively resistive. The slight deviations from the straight line are compatible with an inertial mechanism. Close analysis of the differences shows that $\mathrm{P}_{\mathrm{ex}}$ is slightly above the line during periods when $\mathrm{Q}_{\text {in }}$ is increasing (accelerating) and below it when $Q_{\text {in }}$ is decreasing (decelerating). The slope of the line is not different from characteristic impedance (data not shown).

Figure $3 A$ shows the pressure waveforms measured every $2 \mathrm{~cm}$ from the aortic root to the femoral artery. The propagation of the pressure pulse and the modification of its shape as it propagates distally are clear. During late diastole, pressure decreases almost uniformly from the aortic root to the femoral artery, and there is no evidence of waves. This is shown even more clearly in Fig. $3 B$, which is an isobar contour plot of the same data. During systole and early diastole, the slope of the contours indicate the wave speed. During late diastole, when wave motion is negligible, there are no measurable differences in pressure throughout the length of the aorta, indicating that pressure is a function of time only, not of distance.

In Fig. 4, we compared $\mathrm{P}_{\mathrm{Wk}}$ and $\Delta \mathrm{V}_{\mathrm{Wk}}$ to two independent estimates of proximal aortic volume. Figure $4 \mathrm{~A}$ shows the flow rate measured at the aortic root (i.e., the inflow) and that measured in the aorta at the level of the diaphragm, in the brachiocephalic artery, and in the left subclavian artery (i.e., the outflows). Figure $4 B$ shows the volumes obtained by integrating the measured inflow $\left(\mathrm{V}_{\text {in }}\right)$ and outflows $\left(\mathrm{V}_{\text {out }}\right)$. The hatched area, $\mathrm{V}_{\text {in }}-\mathrm{V}_{\text {out }}$, represents the instantaneous thoracic aortic volume. To determine whether the change in $\mathrm{P}_{\mathrm{Wk}}$ was proportional to the change in thoracic aortic volume (Eq. 1), we plotted $\mathrm{P}_{\mathrm{Wk}}$ (arbitrarily scaled) and our two estimates of thoracic aortic volume [i.e., the difference in integrated inflow and outflow and the calculated volume of the truncated cone (method detailed later)] during one cardiac cycle (Fig. 4C). Finally, to determine how much of the total $\mathrm{V}_{\mathrm{Wk}}$ was contained within the thoracic aorta, we compared $\Delta \mathrm{V}_{\mathrm{Wk}}\left(\Delta \mathrm{V}_{\mathrm{Wk}}=\right.$ $\left.\Delta \mathrm{P}_{\mathrm{Wk}} \times C\right)$ to the difference between inflow and outflow (Fig. $4 D$ ); we found that $45.1 \pm 2.0 \%$ of the total $\mathrm{V}_{\mathrm{Wk}}$ was contained in the aorta above the diaphragm (Table 1).

These results suggest that, under normal experimental conditions, the waveform of $\mathrm{P}_{\mathrm{ex}}$ is very similar in shape to the waveform of flow at the root of the 

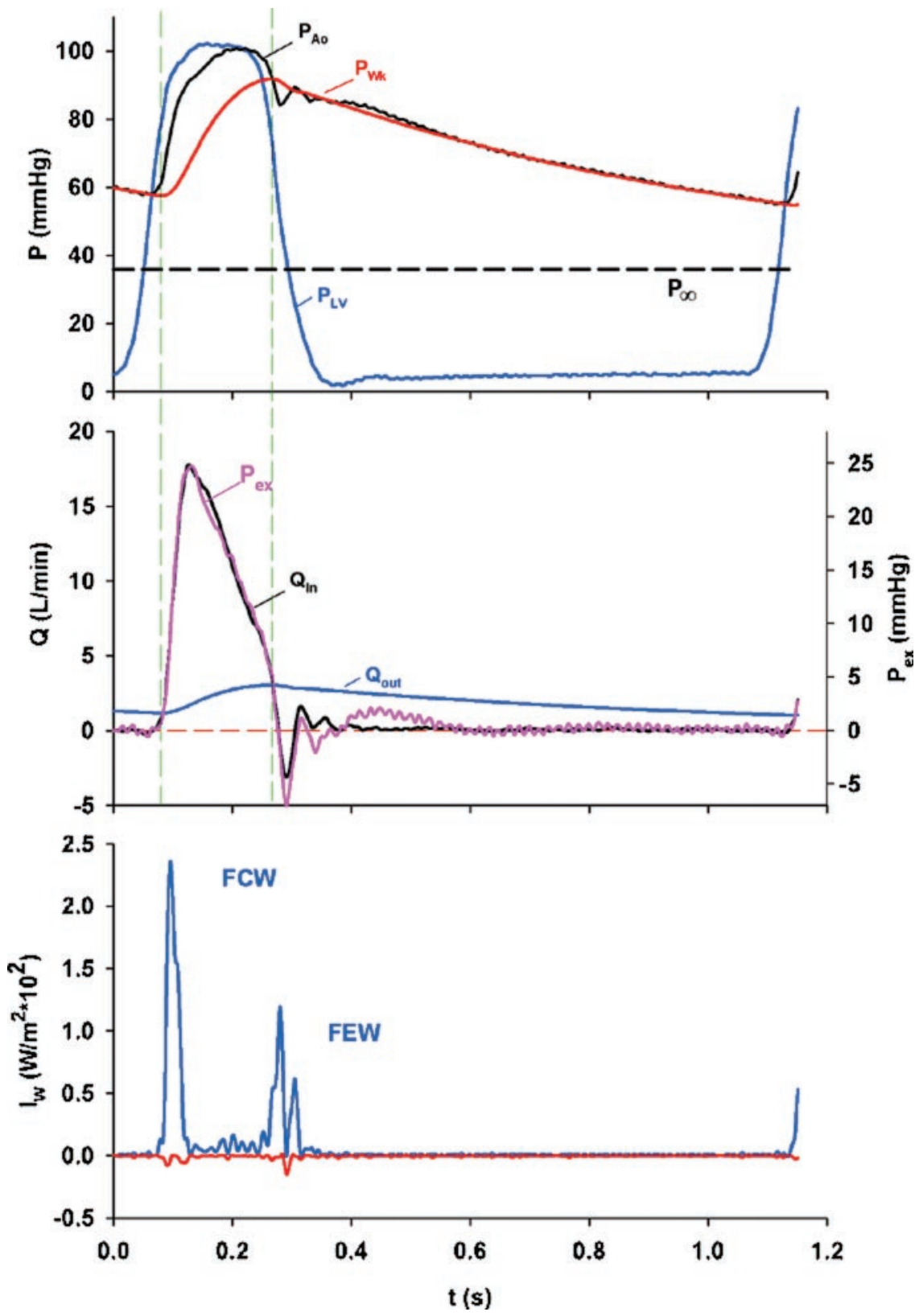

Fig. 1. A: typical aortic root pressure $\left(\mathrm{P}_{\mathrm{Ao}}\right)$, left ventricular $(\mathrm{LV})$ pressure $\left(\mathrm{P}_{\mathrm{LV}}\right)$, calculated windkessel pressure ( $\mathrm{P}_{\mathrm{Wk}}$; red line), and asymptotic pressure $\left(\mathrm{P}_{\infty}\right.$; black dashed line). B: excess pressure $\left(\mathrm{P}_{\mathrm{ex}}\right)$ calculated by subtracting $\mathrm{P}_{\mathrm{Wk}}$ from $\mathrm{P}_{\mathrm{Ao}}$ (pink line), and aortic flow ( $Q_{i n}$; black line) plotted against time with the scales adjusted so that their peak values coincide. Note that they are almost identical in contour. The windkessel is charged when inflow is greater than outflow and vice versa. Two blue vertical dashed lines mark the instants when the inflow equals the outflow ( $\mathrm{Q}_{\text {out }}$; blue line) and $\mathrm{P}_{\mathrm{Wk}}$ is constant. $C$ : wave intensity $\left(\mathrm{I}_{\mathrm{W}}\right)$ analysis. The blue line indicates the intensity of forward-traveling waves; note the (forward) compression wave (FCW) that defines the power expended by the LV in accelerating the stroke volume and the (forward) expansion wave (FEW) that defines the power expended by the relaxing $\mathrm{LV}$ in decelerating the stroke volume. The red line indicates the intensity of backward-traveling waves, which are negligible in magnitude; $t$, time. aorta. This suggests that reflected waves do not have a significant effect on the left ventricle. To explore the effects of reflected waves, we produced backward-traveling waves using a counterpulsation balloon inserted in the abdominal aorta. The inflation and deflation of the balloon was timed so that their effects would be manifest at the aortic valve during ejection. Figure $5 \mathrm{~A}$ shows $\mathrm{P}_{\mathrm{ex}}$ and $\mathrm{Q}_{\text {in }}$ in a normal beat scaled to show the similarity of the two waveforms. Figure $5 B$ shows $\mathrm{P}_{\text {ex }}$ and $Q_{\text {in }}$ measured during the succeeding beat, when the balloon was inflated and deflated. The arrival of the backward compression wave (due to balloon inflation) is evident in early systole, when the pressure and flow waveforms suddenly deviate from each other (a backward compression wave increases pressure and decelerates flow). The arrival of the backward expansion wave (due to balloon deflation) is evident in late sys- tole, when the pressure and flow cross over (a backward expansion wave decreases pressure and accelerates flow).

\section{DISCUSSION}

We assumed that the aortic windkessel is fundamentally and essentially a hydraulic integrator and demonstrated that $\mathrm{P}_{\mathrm{Wk}}$ is proportional to independent estimates of aortic volume. When $\mathrm{P}_{\mathrm{Wk}}$ was subtracted from central $\mathrm{P}_{\mathrm{Ao}}$ to define the pressure difference driving flow into the windkessel, that difference (here called $\mathrm{P}_{\mathrm{ex}}$ ) is directly and quite precisely proportional to the aortic inflow $\mathrm{Q}_{\text {in. }}$. This observation could resolve the long-standing paradox arising from differences between $\mathrm{P}_{\text {Ao }}$ and flow waveforms. The ratio of $\mathrm{P}_{\mathrm{ex}}$ to $\mathrm{Q}_{\text {in }}$ defines a proximal resistance, $R_{\text {prox }}=\mathrm{P}_{\mathrm{ex}} / \mathrm{Q}_{\mathrm{in}}$, that is 


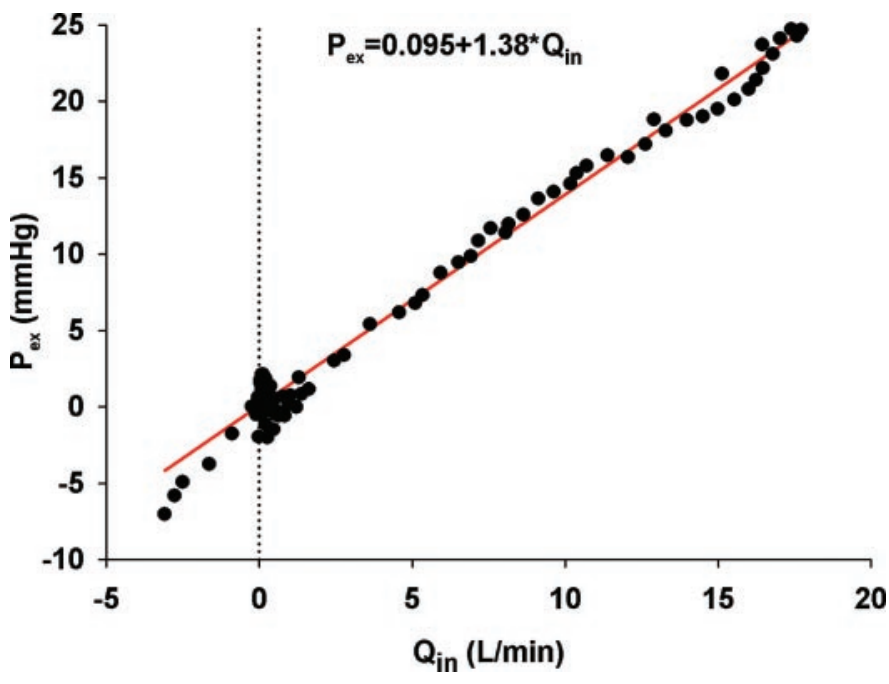

Fig. 2. A plot of $P_{\text {ex }}$ versus $Q_{\text {in }}$ is almost a straight line, suggesting a resistive phenomenon; its slope is not different from characteristic impedance.

not quantitatively different from the characteristic impedance determined by traditional methods (45). We are proposing a way of subdividing $\mathrm{P}_{\text {Ao }}$ (into windkessel and wave components) that could illuminate the complex interaction between the left ventricle and the arterial system.

Frank's windkessel model, however controversial, is still the most popular model of the arterial system (3, 13). It successfully explains diastole as the discharging of a volume integrator in which pressure falls exponentially and uniformly, as we demonstrated in Fig. 3. It has been widely utilized to estimate arterial compliance and stroke volume but, despite its popularity, Frank's windkessel has been frequently criticized for its poor prediction of aortic waveforms, its failure to include wave reflection, and its seemingly inherent implication that wave speed is infinite $(20,28)$. However, the first criticisms are met by our identification of $\mathrm{P}_{\mathrm{ex}}$, which, when added to $\mathrm{P}_{\mathrm{Wk}}$, predicts systolic aortic waveforms precisely and also accounts for wave reflection. The last criticism is meaningful only if one is attempting to explain the decline in aortic diastolic pressure using wave theory. The essence of this paper is the proposition that the decline in aortic diastolic pressure can be explained completely by the decreasing volume of the aorta (as outflow continues in the absence of inflow); we do not attempt to explain it by waves. The explanation is as straightforward and, perhaps, as compelling as the conclusion that the pressure in the bottom of a bathtub decreases because the water drains out of it. Thus the wave speed criticism of the windkessel would appear to be moot.

Other arterial models based on wave theory, the elastic tube model by Womersley $(19,47)$ and the lumped electrical circuit models based on transmission line theory $(1,44)$, may explain the phasic differences in the aortic waveforms, but they introduce other problems of interpretation.
For example, is wave length a simple inverse function of heart rate in diving mammals, which experience profound bradycardia, decreasing their heart rates from $\sim 70$ to $\sim 10$ beats/min? Does the wave length really increase sevenfold? Furthermore, the frequencydomain approach postulates that during diastole, there are identically declining forward and backward pressures, which add to yield the measured pressure (see Fig. 6). In Fig. 6, beat 2 is rather ineffective and produced a very small stroke volume, capable of increasing $\mathrm{P}_{\mathrm{Ao}}$ by only a few millimeters of mercury. Application of our windkessel algorithm shows an excellent fit (Fig. 6A): the monotonic decrease in $\mathrm{P}_{\mathrm{Wk}}$ is interrupted by the small ejection, during which aortic inflow briefly exceeds aortic outflow. Figure $6 B$ shows that calculated $\mathrm{P}_{\mathrm{ex}}$ corresponds to aortic inflow for each beat. Figure 6, $C$ and $D$, illustrates the results of the frequency-domain approach. Forward and backward pressure (Fig. 6C) and velocity (Fig. 6D) waves are calculated. It seems difficult to explain why the backward pressure wave after beat 2 is so small when the preceding beat was large. Similarly, after beat 3 , why is the backward wave so large? What is implied about the persistence of resonant waves of different frequencies by this sequence of beats? As well as the problem of analyzing individual beats, these difficulties may stem from the fundamental assumptions in the established approach.

Since the 1960s, Frank's windkessel model has been simulated using a two-element $R$ - $C$ circuit, a capacitor, and a resistor in parallel (23) and has been analyzed almost exclusively in the frequency domain $(2,7,21$, $23,28,39)$. The later addition of a proximal resistor led to improved prediction of systolic pressure (45). However, in our view, these approaches have not been a wholly satisfactory explanation of the differences between $\mathrm{P}_{\mathrm{Ao}}$ and flow waveforms. Because $\mathrm{P}_{\mathrm{Wk}}$ was not represented in the time domain, it was not clear how well $\mathrm{P}_{\mathrm{Wk}}$ explains the variation in diastolic $\mathrm{P}_{\mathrm{Ao}}$. Because $\mathrm{P}_{\mathrm{Wk}}$ was not subtracted from $\mathrm{P}_{\mathrm{Ao}}$, it was not clear that $\mathrm{P}_{\mathrm{ex}}$ and $\mathrm{Q}_{\mathrm{in}}$ were proportional, thus resolving the differences between $\mathrm{P}_{\mathrm{Ao}}$ and flow waveforms.

\section{The Windkessel as a Reservoir}

To determine how precisely changes in $\mathrm{P}_{\mathrm{Wk}}$ were proportional to changes in aortic volume, we scaled $\mathrm{P}_{\mathrm{Wk}}$ arbitrarily and compared it with two independent estimates of the change in thoracic aortic volume. For the first estimate, we isolated the segment of the aorta between the aortic root and the diaphragm and then estimated its volume change by comparing the inflow (aortic root flow) to the outflows (flows in the brachiocephalic and left subclavian arteries and in the aorta at the diaphragm). For the second estimate, we measured aortic diameter at the root and at the diaphragm and, by assuming that the intervening segment was a truncated cone, we calculated the change in total volume. Both these estimates of blood volume change correlated very closely with the variation of $\Delta \mathrm{V}_{\mathrm{Wk}}$, but there were small differences (Fig. $4 C$ ). The inflow-outflow 

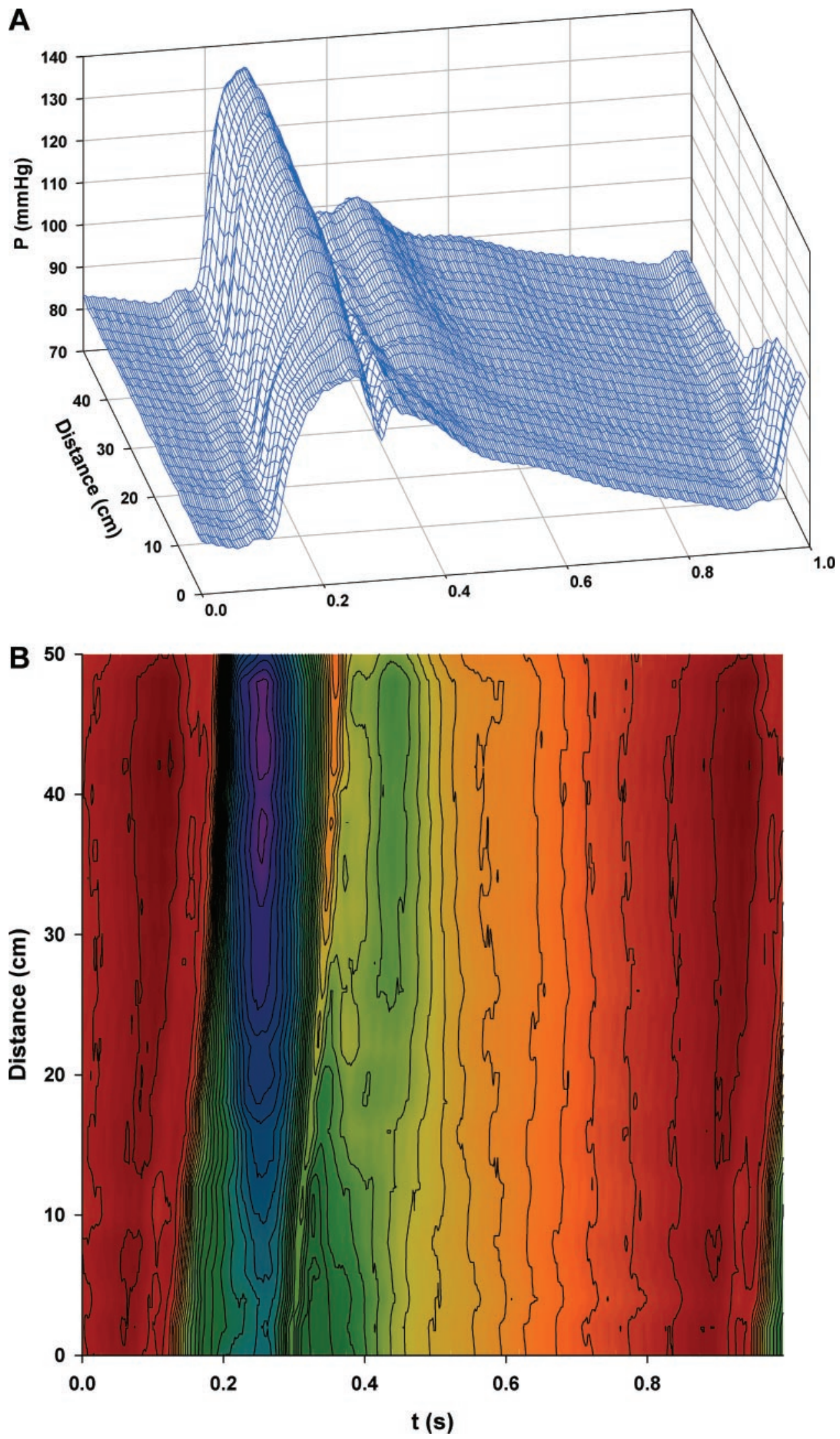

Fig. 3. A: three-dimensional plot of $\mathrm{P}_{\text {Ao }}$ versus time and distance (by $2-\mathrm{cm}$ increments, from the aortic root to the femoral artery). Data are from a single dog. $B$ : isobar contour plot of the same data (each line indicates an increment of $2 \mathrm{mmHg}$ ). Note that, during late diastole, pressure is dependent on time but is independent of distance. 

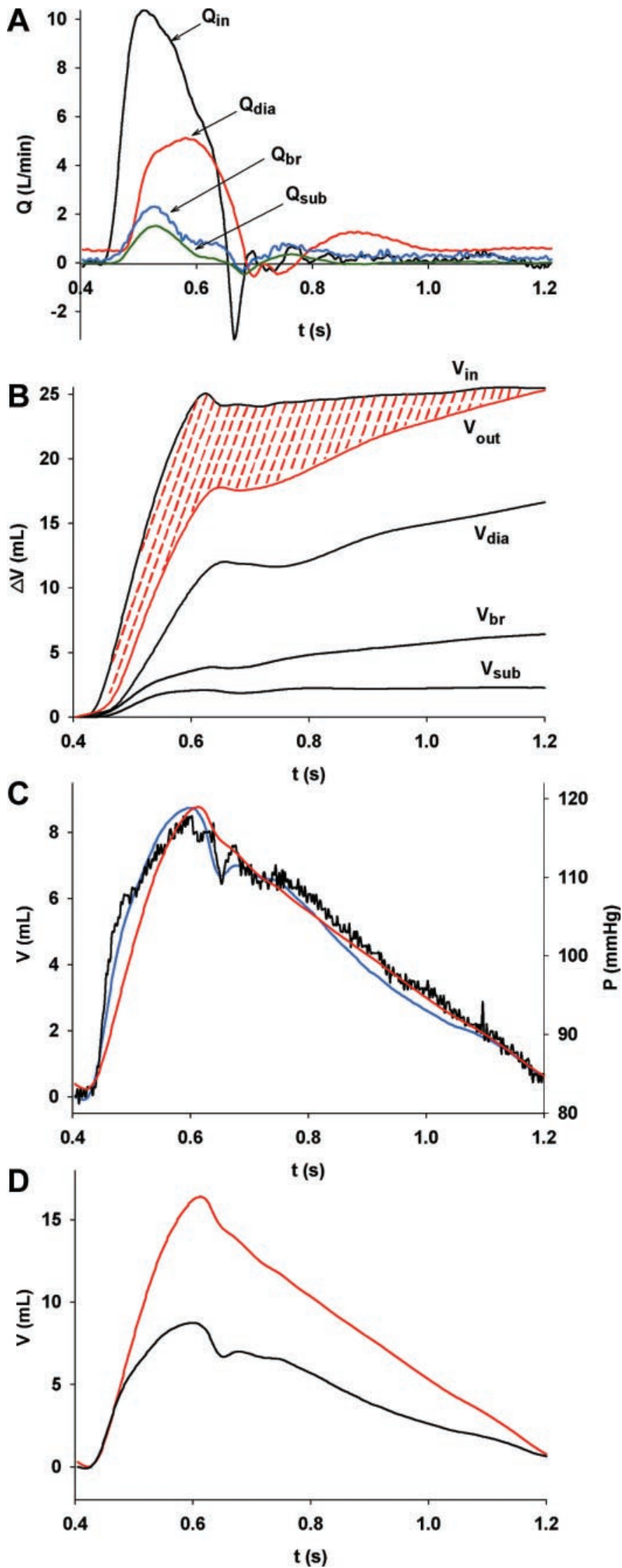

difference and the calculated volume both led $\mathrm{P}_{\mathrm{Wk}}$ during early ejection, which may be due to the fact that the ejected stroke volume was not completely distributed through the windkessel at that time. Also, after closure of the aortic valve, the inflow-outflow difference was greater than $\mathrm{P}_{\mathrm{Wk}}$ and the calculated volume. This may be due to the effect of forward diastolic flow at the diaphragm, which momentarily decreased the integral of diaphragmatic flow (see Fig. $4 A$ ), thus increasing the inflow-outflow difference.

To determine how the magnitude of the calculated change in total $\mathrm{V}_{\mathrm{Wk}}$ compared with our estimates of thoracic aortic volume, we converted $\Delta \mathrm{P}_{\mathrm{Wk}}$ to $\Delta \mathrm{V}_{\mathrm{Wk}}$ (by multiplying by $C$ ) and compared it with the inflowoutflow difference (see Fig. $4 D$ ). The results indicate that $45.1 \pm 2.0 \%$ of the total $\mathrm{V}_{\mathrm{Wk}}$ is contained in the aorta within the thorax. To our knowledge, this is the first such measurement of $\mathrm{V}_{\mathrm{Wk}}$. On the basis of Westerhof's data (44) from his electrical model for the arterial system, Stergiopolus (37) suggested that up to $65 \%$ of compliance is contained in the aortic trunk (ascending, descending, and thoracic aorta), an estimate that is not substantially different from ours, given that we did not consider the volume of the large thoracic branches of the aorta.

\section{Implications of "Waves"}

The wave nature of arterial flow is well established and universally accepted (2). It is also well established, but apparently not widely recognized, that pressure and flow are so inextricably linked in arterial waves that waves should be thought of as pressure/flow waves rather than separate pressure and flow waves. All waves involve an interchange between different forms of energy (15); in arterial waves, this interchange is between the elastic energy of the wall (mediated by the pressure) and the kinetic energy of the flow. This means that the change in pressure caused by an arterial wave is proportional to the change in flow that it causes (9). The relationship between the instantaneous change in pressure and the instantaneous change in flow is given by the water hammer equation $(20,23)$.

Different usages of "wave" demand that we reconsider its definition. As we have written elsewhere (11, $25,26,40,43)$, using wave intensity analysis, we deal

Fig. 4. A: thoracic aortic inflow $\left(\mathrm{Q}_{\text {in }}\right)$ and outflows $\left(\mathrm{Q}_{\text {dia }}\right.$, flow of the aorta at the diaphragm; $\mathrm{Qbr}_{\mathrm{br}}$, flow of the brachiocephalic artery; $\mathrm{Q}_{\mathrm{sub}}$, flow of the subclavian artery). The small branches of arteries were occluded. $B$ : integrals of thoracic inflow and outflows (i.e., the volume coming into and flowing out of the thoracic aorta during one complete cycle). Note that the hatched area, the difference between inflow and summated outflows, represents the instantaneous change in windkessel volume $\left(\mathrm{V}_{\mathrm{wk}}\right)$. $\mathrm{V}_{\text {in }}$, inflow volume; $\mathrm{V}_{\text {out }}$, outflow volume; $\mathrm{V}_{\text {dia }}$, volume of the aorta at the diaphragm; $\mathrm{V}_{\mathrm{br}}$, volume of the brachiocaphalic artery; $\mathrm{V}_{\mathrm{sub}}$, volume of the subclavian artery. $C$ : volume change in the thoracic aorta calculated by crystal measurements (black line) and by differences of inflow and outflows (blue line) plotted with the calculated $\mathrm{P}_{\mathrm{Wk}}$ (red line). They are similar in shape. $D$ : total, absolute volume change of the whole arterial system during a cycle $\left(\Delta \mathrm{V}_{\mathrm{wk}}\right.$; red line $)$ compared with the volume change in the thoracic section (inflow minus outflow; black line). Approximately $45 \%$ of the total $\mathrm{V}_{\mathrm{Wk}}$ is contained in the thoracic aorta. 
Table 1. Hemodynamic data, curve-fitting parameters, and fraction of the total windkessel volume contained within the thoracic aorta

\begin{tabular}{|c|c|c|c|c|c|c|c|}
\hline Dogs & $\begin{array}{l}\text { HR, beats/ } \\
\text { min }\end{array}$ & $\begin{array}{l}\mathrm{P}_{\mathrm{Ao}}, \\
\mathrm{mmHg}\end{array}$ & $\begin{array}{l}\mathrm{CO}, \\
1 / \mathrm{min}\end{array}$ & $\tau, \mathrm{s}$ & $\begin{array}{c}C, \\
\mathrm{~cm}^{3} / \mathrm{mmHg}\end{array}$ & $\begin{array}{c}\mathrm{P}_{\infty}, \\
\mathrm{mmHg}\end{array}$ & $\begin{array}{l}\mathrm{V}_{\mathrm{Wk}, \text { Thor }} / \\
\mathrm{V}_{\mathrm{Wk}, \text { Total }}\end{array}$ \\
\hline 1 & 68.7 & 82.7 & 1.31 & 1.13 & 0.36 & 29.5 & 0.47 \\
\hline 2 & 62.1 & 74.7 & 1.11 & 1.20 & 0.64 & 39.7 & 0.38 \\
\hline 4 & 89.6 & 91.7 & 1.05 & 1.22 & 0.26 & 26.0 & 0.49 \\
\hline 5 & 96.2 & 80.0 & 1.59 & 1.03 & 0.50 & 25.1 & 0.57 \\
\hline 6 & 66.2 & 94.3 & 1.67 & 0.96 & 0.60 & 50.8 & 0.57 \\
\hline 9 & 54.0 & 81.0 & 0.92 & 1.09 & 0.43 & 48.1 & 0.48 \\
\hline 10 & 70.3 & 89.0 & 1.64 & 1.13 & 0.59 & 46.0 & 0.40 \\
\hline 11 & 68.0 & 57.3 & 1.35 & 0.89 & 0.60 & 17.6 & 0.36 \\
\hline 12 & 47.0 & 91.0 & 0.85 & 1.11 & 0.37 & 48.0 & 0.48 \\
\hline 13 & 66.8 & 96.7 & 1.69 & 1.01 & 0.47 & 40.5 & 0.45 \\
\hline 14 & 51.0 & 70.3 & 0.99 & 0.44 & 0.48 & 34.5 & 0.40 \\
\hline 15 & 65.2 & 93.3 & 1.63 & 1.07 & 0.55 & 45.4 & \\
\hline
\end{tabular}

$\mathrm{HR}$, heart rate; $\mathrm{P}_{\mathrm{Ao}}$, mean aortic pressure; $\mathrm{CO}$, cardiac output; $\tau$, diastolic exponential time constant; $C$, compliance; $\mathrm{P}_{\infty}$, asymptotic pressure; $\mathrm{V}_{\mathrm{Wk}}$, Thor, windkessel volume contained in the thoracic aorta; $\mathrm{V}_{\mathrm{Wk}}$, Total, total windkessel volume.
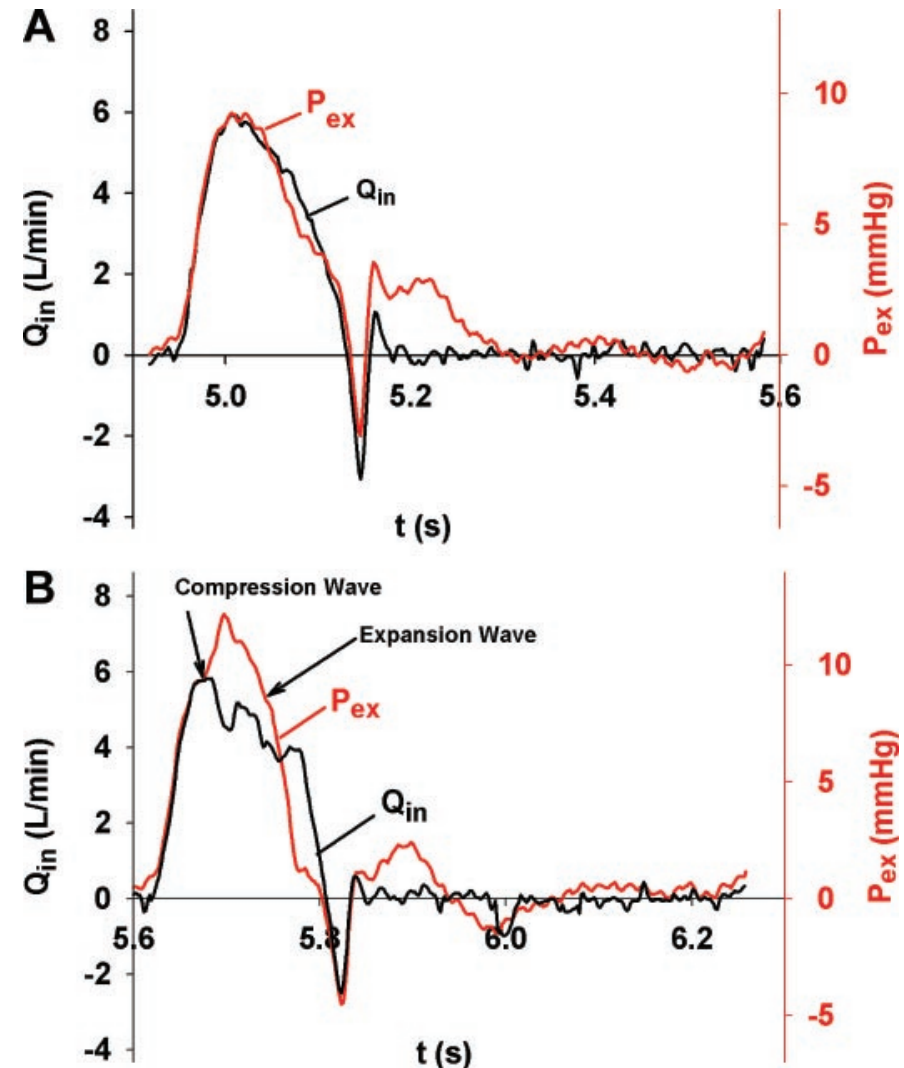

Fig. 5. A: $\mathrm{P}_{\mathrm{ex}}$ (red line) and $\mathrm{Q}_{\text {in }}$ (black line) in a normal beat, scaled so that their peak values coincide. Note the similarity in the shape of the two waveforms. $B: P_{\text {ex }}$ (red line) and $Q_{\text {in }}$ (black line) in the following beat, during which the counterpulsation balloon in the aorta just proximal to the iliac bifurcation was inflated and deflated to cause an early backward compression wave (increased pressure and decreased flow), followed by a backward expansion wave (decreased pressure and increased flow), as indicated. The arrows indicated the time of arrival of the backward compression and expansion waves generated by the balloon. with the propagation of infinitesimal wavefronts, the summation of which we define as waves [e.g., the forward-traveling compression wave that increases $\mathrm{P}_{\text {Ao }}$ and accelerates the stroke volume (25); see Fig. 1C]. This is consistent with the classical definition-a propagated disturbance (15). In our view, it is this forwardtraveling compression wave, in particular, that is propagated toward the periphery and reflected to arrive back at the aortic valve before the end of left ventricular ejection in older people and others with stiffened aortas and increased wave speeds [i.e., Murgo's type A pressure waveform (21)]. The incremental wavefronts are defined by the changes in pressure and velocity during each sampling interval, and it is the temporal summation of these successive wavefronts that give rise to pressure and velocity "waveforms" (this should be contrasted with Fourier transform-based impedance analyses, in which the measured pressure and velocity waveforms are treated as the superposition of sinusoidal wavetrains with different frequencies).

The one-dimensional theory of waves in elastic tubes implies that the differences between the pressure and flow waveforms measured in the root of the aorta can only be the result of backward waves arising from reflection sites $(2,23,28)$ (see Fig. 6). Despite the consensus that there are few waves during late diastole $(37,38)$, using the impedance approach, the diastolic contour has to be accounted for as the sum of forward- and backward-traveling waves $(2,21,28,39)$. Furthermore, this mathematical solution requires that the amplitudes of the two waves are equal and exactly one-half the amplitude of the variation in aortic pressure during this interval $(2,23,28)$.

On the other hand, according to our interpretation, the similarity of $P_{\text {ex }}$ and $Q_{i n}$ and the results of wave intensity analysis imply that the $\mathrm{P}_{\mathrm{ex}}$ and $\mathrm{Q}_{\mathrm{in}}$ waveforms can be almost completely explained by forwardtraveling waves (i.e., the forward compression and ex- 
Fig. 6. Comparative analysis of a series of irregular beats using the windkessel-wave method ( $A$ and $B$ ) and the impedance method $(C$ and $D)$. $A$ : calculated $\mathrm{P}_{\mathrm{Wk}}$ (red line) fits the measured $\mathrm{P}_{\text {Ao }}$ (black line) for each beat. $B$ : calculated $\mathrm{P}_{\mathrm{ex}}$ (pink line) has similar contours as $\mathrm{Q}_{\text {in }}$ (black line) for each beat. $C$ and $D$ : forward ( $\mathrm{P}_{\text {forward }}$; blue line) and backward ( $\mathrm{P}_{\text {backward; red line) pres- }}$ sures $(C)$ and forward ( $U_{\text {forward; blue }}$ line) and backward ( $U_{\text {backward; }}$ red line) velocities $(D)$ calculated using the impedance method. See text for details.
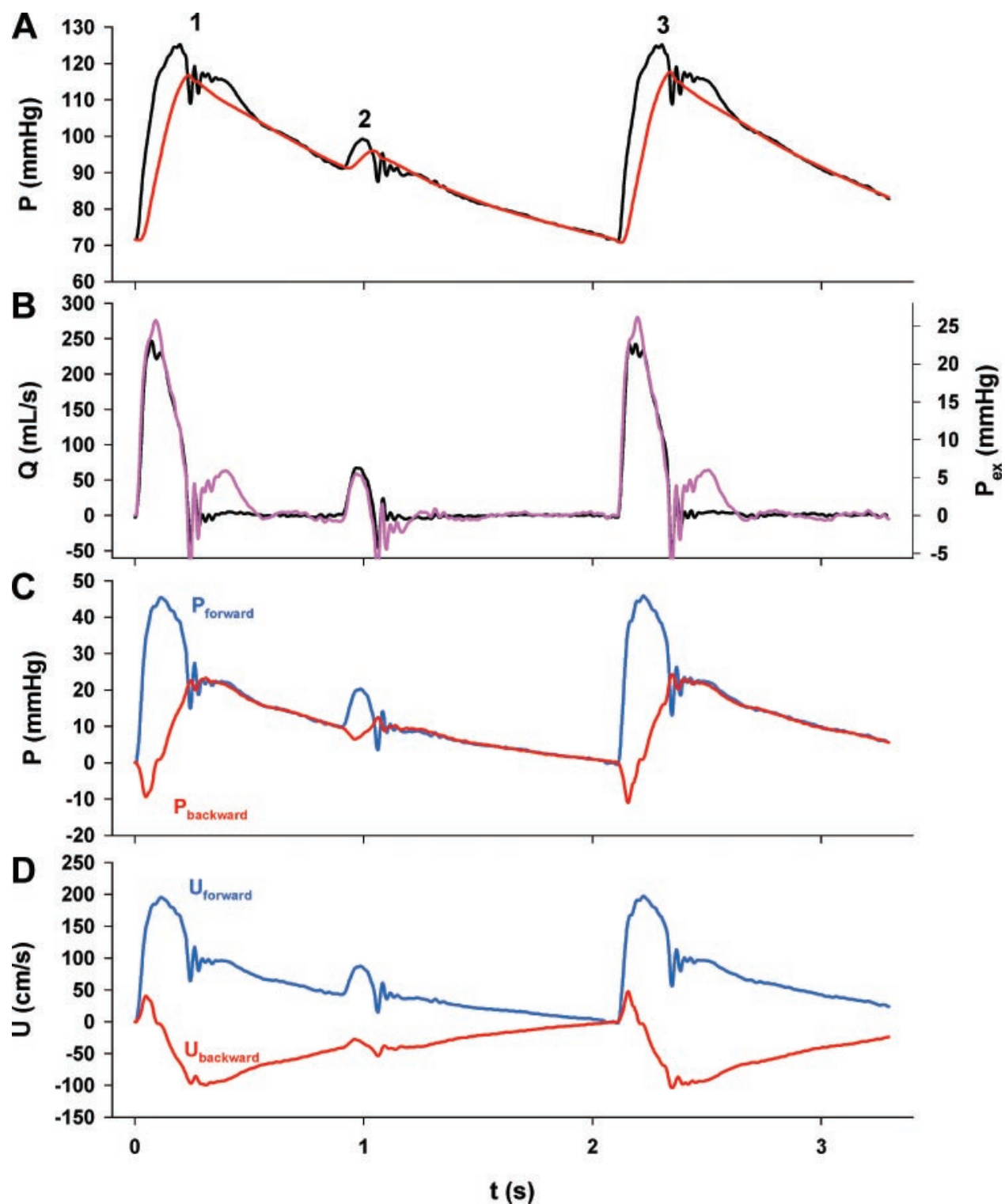

pansion waves generated by the left ventricle). To better assess the possible contribution of backwardtraveling waves, we introduced a counterpulsation balloon in the abdominal aorta and triggered it so that a backward compression wave (quickly followed by a backward expansion wave) would arrive at the aortic valve during ejection (see Fig. 5). The backward compression wave, caused by the inflation of the balloon, increased $\mathrm{P}_{\mathrm{ex}}$ but decreased $\mathrm{Q}_{\mathrm{in}}$ (Fig. 5B). The immediately following backward expansion wave, caused by the deflation of the balloon, decreased $\mathrm{P}_{\mathrm{ex}}$ but increased $\mathrm{Q}_{\text {in. }}$ These results support the conclusion that, after isolating $\mathrm{P}_{\mathrm{Wk}}$ from $\mathrm{P}_{\mathrm{Ao}}$, the waveform of $\mathrm{P}_{\mathrm{ex}}$ is identical to that of $Q_{\text {in }}$ if there are no backward waves but different in contour if there are.

Furthermore, we note that the success of lumpedparameter electrical analog models of the arteries that implicitly assume a linear relationship between $\mathrm{P}$ and $\mathrm{Q}$ implies that there are no significant reflected waves in the root of the aorta. One of the most successful electrical circuit models is the three-element windkessel (45), which, following Broemser and Ranke (4), was proposed by Westerhof and is deferentially called the westkessel by some authors. The westkessel added a characteristic impedance, $\rho c / A$, in series and proximal to Frank's windkessel model, a parallel $R-C$ circuit. Its input is a current source, $Q_{i n}$, and the outputs are the pressure across the characteristic impedance $\left(\mathrm{P}_{\mathrm{c}}=\right.$ $\left.\rho c / A \times Q_{i n}\right)$ and the windkessel pressure $\left(\mathrm{P}=\mathrm{P}_{\mathrm{c}}+\right.$ $\left.\mathrm{P}_{\mathrm{Wk}}\right)$. The pressure across the characteristic impedance is defined by the water hammer equation, $\mathrm{P}_{\mathrm{c}}=\rho c / A \times$ $Q_{\text {in }}$, which shows the pressure-flow relation for forward waves. In the time domain, the westkessel model describes the $\mathrm{P}_{\text {Ao }}$ waveform as just the summation of a forward-traveling wave and the windkessel, which is the time-varying reservoir pressure. There is no backward wave in this model. That the westkessel could be used to successfully simulate the aortic waveforms of numerous species suggests that reflected waves are negligible in most of those species. 


\section{Comparison to Impedance Analysis}

It is not surprising that there should be similarities between our time-domain analysis and the established frequency-domain analysis. First, our definition of $\mathrm{P}_{\mathrm{Wk}}$ arises from the assumption that the windkessel is a hydraulic integrator that corresponds to a two-element windkessel (i.e., a capacitance $C$ and a distal resistance $R$ connected to an outflow compartment whose pressure, $\mathrm{P}_{\infty}$, is not necessarily venous pressure) ${ }^{1}$ studies of the impulse response approximate our description of the windkessel, differing only because left ventricular ejection is somewhat sustained and not a pure impulse $(5,8,14,35)$. Second, our $P_{\text {ex }}$-to- $Q_{\text {in }}$ ratio also seems to correspond exactly to characteristic impedance, which, in the electrical analog, separates the flow source from the integrator in the three-element windkessel (45). As Westerhof (45) originally pointed out and as Quick et al. (28) noticed, the operation of characteristic impedance on aortic inflow yields a pressure that is proportional to flow, thus equivalent to our $\mathrm{P}_{\mathrm{ex}}$. They termed this pressure "reflectionless," which is consistent with our conclusion that $\mathrm{P}_{\mathrm{ex}}$ can be almost entirely explained by forward-traveling waves.

Thus the reader may be satisfied that our results are consistent with established work but may not believe that our approach has any important advantages. We believe there are three. First and perhaps foremost, the time-domain identification of $\mathrm{P}_{\mathrm{Wk}}$ is eminently intuitive and easy to explain. The concept of a hydraulic integrator (based on the classical theory) is obvious to every student of physiology who has seen the classical diagrams, and it seems unfortunate that the workings of this simple device should have been so obscured by the frequency-domain analysis. Second, on a beat-tobeat basis, the time-domain representation of $\mathrm{P}_{\mathrm{Wk}}$ and $\mathrm{V}_{\mathrm{Wk}}$ can be related directly to primary hemodynamic measurements-pressures, dimensions, and flows-so interpretation is more straightforward, and new insights may be expected. Third, wave intensity analysis $(10,11,16,36,40)$ provides for wave motion a similarly direct representation, identifying forward- and backward-traveling compression and expansion waves in the time domain, whereas variations of impedance spectra that are subtle and perhaps ambiguous are the only evidence of alterations in wave motion in the frequency domain. Having isolated $\mathrm{P}_{\mathrm{Wk}}$ and continuing to employ wave-intensity analysis, we believe we have an alternative paradigm that will increase our understanding of arterial hemodynamics.

In conclusion, we feel that our proposed interpretation of aortic hemodynamics has some fundamental advantages. Our division of the pressure into $\mathrm{P}_{\mathrm{Wk}}$ and $\mathrm{P}_{\mathrm{ex}}$ is based on recognized mechanistic properties of the arteries, the capacitive nature of the elastic arter-

\footnotetext{
${ }^{1}$ As yet, this phenomenon is poorly understood. However, it is consistent with the correction invoked in the determination of mean circulatory pressure (29), it has been studied quite extensively by Magder and collaborators $(17,18,34)$, and it may be related to Burton's critical closing pressure (6).
}

ies, and the wavelike nature of arterial flow. To the contrary, the description of the pressure waveform as the superposition of sinusoidal waves has no mechanical basis but is based on the mathematical observation that any periodic waveform can be represented by a Fourier series (or, in fact, by any orthogonal basis functions). Just because a waveform can be representated by sinusoidal waves, it does not follow that it was generated by sinusoidal waves. By ascribing the bulk of the pressure variation during diastole to the windkessel process, we find that the $\mathrm{P}_{\mathrm{ex}}$ waveform is virtually identical to the measured flow waveform. This implies that reflected waves are not very significant in the ascending aorta under normal conditions, which is consistent with previous observations. Finally, because $\mathrm{P}_{\mathrm{Wk}}$ and $\mathrm{P}_{\mathrm{ex}}$ have a mechanistic basis, their separation could have implications about the mechanical linkage between the left ventricle and the arteries and therefore to a better understanding of the energetics of ventricular contraction. These implications require further study.

We acknowledge the excellent technical support provided by Cheryl Meek, Gerald Groves, and Rozsa Sas.

This study was supported by a grant-in-aid from the Heart and Stroke Foundation of Alberta (Calgary, Alberta, Canada) and by Canadian Institutes for Health Research (Ottawa, Ontario, Canada) Grant-In-Aid MT-15418 (to J. V. Tyberg). A. B. O’Brien was supported by the Dale and Rushton Fund of The Physiological Society, N. G. Shrive holds a Killam Professorship, and J. V. Tyberg is a Heritage Scientist of the Alberta Heritage Foundation for Medical Research (Edmonton, Alberta, Canada).

\section{REFERENCES}

1. Avolio AP. Multi-branched model of the human arterial system. Med Biol Eng Comput 18: 709-718, 1980.

2. Berger DS, Li JKJ, Laskey WK, and Noordergraaf A. Repeated reflection of waves in the systemic arterial system. Am J Physiol Heart Circ Physiol 264: H269-H281, 1993.

3. Berne RM and Levy MN. Cardiovascular Physiology. St. Louis, MO: Mosby, 2001, p. 1-312.

4. Broemser $\mathbf{P}$ and Ranke FO. Über die Messung des Schlagvolumens des Herzens auf unblutigem Weg. Z Biol 90: 467, 1930.

5. Burkhoff D, Alexander J Jr, and Schipke J. Assessment of Windkessel as a model of aortic input impedance. Am J Physiol Heart Circ Physiol 255: H742-H753, 1988.

6. Burton AC. On the physical equilibrium of small blood vessels. Am J Physiol 164: 319-329, 1951.

7. Castelain V, Herve P, Lecarpentier Y, Duroux $\mathbf{P}$, Simonneau G, and Chemla D. Pulmonary artery pulse pressure and wave reflection in chronic pulmonary thromboembolism and primary pulmonary hypertension. J Am Coll Cardiol 37: 10851092, 2001.

8. Fitchett DH. LV-arterial coupling: interactive model to predict effect of wave reflections on LV energetics. Am J Physiol Heart Circ Physiol 261: H1026-H1033, 1991.

9. Frank O. Die Theorie der Pulswellen. Z Biol 85: 91-130, 1926.

10. Grant DA, Hollander E, Skuza EM, and Fauchere JC. Interactions between the right ventricle and pulmonary vasculature in the fetus. J Appl Physiol 87: 1637-1643, 1999.

11. Hollander EH, Wang JJ, Dobson GM, Parker KH, and Tyberg JV. Negative wave reflections in pulmonary arteries. Am J Physiol Heart Circ Physiol 281: H895-H902, 2001.

12. Karamanoglu M, Gallagher DE, Avolio AP, and O'Rourke MF. Functional origin of reflected pressure waves in a multibranched model of the human arterial system. Am J Physiol Heart Circ Physiol 267: H1681-H1688, 1994.

13. Kunihiko O, Keisuke T, Akikazu T, and Kumada M. New Textbook of Physiology. Tokyo: Bunkoudou, 1996, p. 1-571. 
14. Laxminarayan S, Sipkema $\mathbf{P}$, and Westerhof N. Characterization of the arterial system in the time domain. IEEE Trans Biomed Eng 25: 177-184, 1978.

15. Lighthill MJ. Waves in Fluids. Cambridge: Cambridge Univ. Press, 1978, p. 106.

16. MacRae JM, Sun YH, Isaac DL, Dobson GM, Cheng CP, Little WC, Parker KH, and Tyberg JV. Wave-intensity analysis: a new approach to left ventricular filling dynamics. Heart Vessels 12: 53-59, 1997.

17. Magder S. Starling resistor versus compliance. Which explains the zero-flow pressure of a dynamic arterial pressure-flow relation? Circ Res 67: 209-220, 1990.

18. Magder S. Vascular mechanics of venous drainage in dog hindlimbs. Am J Physiol Heart Circ Physiol 259: H1789-H1795, 1990.

19. McDonald DA. The relationship between pulsatile pressure and flow. In: Blood Flow in Arteries. London: Arnold, 1974, p. $315-380$.

20. Milnor WR. Hemodynamics. Baltimore, MD: Williams \& Wilkins, 1989, p. 42-47.

21. Murgo JP, Westerhof N, Giolma JP, and Altobelli SA Aortic input impedance in normal man: relationship to pressure wave forms. Circulation 62: 105-116, 1980.

22. Nichols WW and O'Rourke MF. McDonald's Blood Flow in Arteries. Philadelphia, PA: Lea \& Febiger, 1990, p. 251-267.

23. Nichols WW and O'Rourke MF. McDonald's Blood Flow in Arteries. New York: Arnold, 1998.

24. Noordergraaf A. The Arterial Trees. Circulatory System Dynamics. New York: Academic, 1978, p. 105-156.

25. Parker KH and Jones CJH. Forward and backward running waves in the arteries: analysis using the method of characteristics. J Biomech Eng 112: 322-326, 1990.

26. Parker KH, Jones CJH, Dawson JR, and Gibson DG. What stops the flow of blood from the heart? Heart Vessels 4: 241-245, 1988.

27. Pedley TJ. Fluid Dynamics of Large Blood Vessels. Cambridge: Cambridge Univ. Press, 2001.

28. Quick CM, Berger DS, and Noordergraaf A. Constructive and destructive addition of forward and reflected arterial pulse waves. Am J Physiol Heart Circ Physiol 280: H1519-H1527, 2001.

29. Rothe CF and Drees JA. Vascular capacitance and fluid shifts in dogs during prolonged hemorrhagic hypotension. Circ Res 38: 347-356, 1976

30. Rowlands S. Is the arterial pulse a soliton? J Biol Phys 10: 199-200, 1982.

31. Russell JS. Report of the Committee on Waves. Report of the 7th Meeting of the British Association for the Advancement of Science in Liverpool in 1837. London: Murray, 1838, p. 417-496.

32. Russell JS. Report of the Committee on Waves. Report of the 14th Meeting of the British Association for the Advancement of Science in York in 1844. London: Murray, 1845, p. 311-390.

33. Sagawa K, Lie RK, and Schaefer J. Translation of Otto Frank's paper "Die Grundform des Arteriellen Pulses"
Zeitschrift fur Biologie 37: 483-526 (1899). J Mol Cell Cardiol 22: 253-277, 1990.

34. Shrier I, Hussain SNA, and Magder S. Effect of carotid sinus stimulation on resistance and critical closing pressure of the canine hindlimb. Am J Physiol Heart Circ Physiol 264: H1560 H1566, 1993.

35. Sipkema P, Westerhof $\mathbf{N}$, and Randall OS. The arterial system characterised in the time domain. Cardiovasc Res 14: 270-279, 1980 .

36. Smiseth OA, Thompson CR, Lohavanichbutr K, Abel JG, Miyagishima RT, Lichtenstein SV, and Bowering J. The pulmonary venous systolic flow pulse-its origin and relationship to left atrial pressure. J Am Coll Cardiol 34: 802-809, 1999.

37. Stergiopulos N, Meister JJ, and Westerhof N. Evaluation of methods for estimation of total arterial compliance. Am J Physiol Heart Circ Physiol 268: H1540-H1548, 1995.

38. Stergiopulos $\mathbf{N}$, Segers $\mathbf{P}$, and Westerhof $\mathbf{N}$. Use of pulse pressure method for estimating total arterial compliance in vivo. Am J Physiol Heart Circ Physiol 276: H424-H428, 1999.

39. Stergiopulos N, Westerhof BE, and Westerhof N. Physical basis of pressure transfer from periphery to aorta: a model-based study. Am J Physiol Heart Circ Physiol 274: H1386-H1392, 1998.

40. Sun YH, Anderson TJ, Parker KH, and Tyberg JV. Waveintensity analysis: a new approach to coronary dynamics. $J$ Appl Physiol 89: 1636-1644, 2000.

41. Ter Keurs HEDJ and Tyberg JV. Control of the circulation: an integrated view. In: Comprehensive Human Physiology: From Cellular Mechanism to Integration, edited by Greger $\mathrm{R}$ and Windhorst U. Heidelberg, Germany: Springer-Verlag, 1996, p. 1995-2014.

42. Tyberg JV, Belenkie I, Manyari DE, and Smith ER. Ventricular interaction and venous capacitance modulate left ventricular preload. Can J Cardiol 12: 1058-1064, 1996.

43. Wang JJ. Wave Propagation in a Model of the Human Arterial System (PhD Thesis). London: Imperial College, 1977.

44. Westerhof N, Bosman F, deVries CJ, and Noordergraaf A. Analogue studies of the human systemic arterial tree. J Biomech 2: 121-143, 1969.

45. Westerhof N, Sipkema P, van den Bos GC, and Elzinga G. Forward and backward waves in the arterial system. Cardiovasc Res 6: 648-656, 1972.

46. Whitham GB. Linear and Nonlinear Waves. New York: Wiley, 1974.

47. Womersley JR. Oscillatory flow in arteries: the reflection of the pulse wave at junctions and rigid inserts in the arterial system. Phys Med Biol 2: 178-187, 1958.

48. Yin FCP and Liu Z. Estimating arterial resistance and compliance during transient conditions in humans. Am $J$ Physiol Heart Circ Physiol 257: H190-H197, 1989.

49. Zhou J and Fung YC. The degree of nonlinearity and anisotropy of blood vessel elasticity. Proc Natl Acad Sci USA 94: 14255-14260, 1997. 